\title{
Study on the Reform of Rural Land Law System
}

\author{
JIN JIN
}

Xi'an International University, Business school, Xi'an, Shaanxi ,China

8402111120@qq.com

Keywords: Study, Reform, Rural Land Law, System

\begin{abstract}
Chinese agricultural development mode is extensive, the rural finance agriculture supports is weak, the structure of the rural labor is deteriorated, the enthusiasm of the farmers to grow grain is declining, the rapid development of industrialization and urbanization has aggravated the encroachment of agricultural land, and the food security is faced with multiple pressure such as huge population and reduced agricultural land area. Therefore, in order to promote the historical task of agricultural modernization in the process of industrialization and urbanization, we must explore the development law of rural land system, consolidate and strengthen the foundation of agriculture, and construct the rural land system in line with Chinese characteristics.
\end{abstract}

\section{Introduction}

China's "Twelfth Five-Year Plan for National Economic and Social Development," pointed out that adhere to the road of agricultural modernization with Chinese characteristics, the protection of national food security as the primary objective, accelerate the transformation of agricultural development, improve agricultural production capacity, anti-risk ability And market comprehensive ability. Along with this goal, the rural land system reform problems also surfaced. Whether the current rural land system adapts to the road of agricultural modernization with Chinese characteristics, whether the existing rural land system can provide reliable guarantee for the national food security, how to reform the current rural land system, and so on, re-placed us before.

It is clear that the agrarian reform is the forerunner and the foundation of the rural reform and the land reform is the foundation of the reform of the rural areas. As a result, the land reform has become the mainstay of the Chinese revolution, construction and reform. Is the key to the success or failure of China's revolution, construction and reform. History has already made eye-catching remarks. When the land policy adapts to the development of the productive forces, the peasants are displaced, the economy is depressed, and even the state is in turmoil. To learn from the history, we must conscientiously explore the law of the development of rural land system, consolidate and strengthen the status of agricultural base, and build a rural land system in line with Chinese characteristics, in order to advance the historical task of agricultural modernization in the process of industrialization and urbanization.

But there are some unfavorable factors to further deepen the reform of China's rural land system, urban and rural development put forward an urgent requirement. From the fundamental point of view, the prominent contradictions in the current agricultural land system, mainly in three areas. One is the contradiction between the small scale of farmer's management and extensive land management. Under the circumstance that a large number of agricultural laborers go out to work and the circulation of land contracting right is not smooth, even a large number of abandoned farmland waste phenomenon; second is to accelerate industrialization and urbanization and promote the emergence of the contradiction of land supply shortage; Third, the land expropriation compensation system is not perfect, leading to the interests of farmers against the problem, in some places is also quite serious and become a prominent problem affecting local stability. The root cause of these contradictions lies in the fact that the main body of the rural collective land property right is empty, the ownership relationship is unclear, the contractual management right of the land is unstable; the farmland fragmentation management, the land circulation is difficult, and the moderate scale management is 
difficult to realize; The system of land requisition is lacking, and the farmers' land rights cannot be guaranteed effectively.

In fact, the establishment of rural land family contract management system did not exhaust the limits of rural land system innovation. In recent years, a series of profound changes have taken place in China's rural areas, which not only changed the external environment of rural land system innovation, but also put forward new requirements for the reform of rural land system. The author firmly believes that through a series of agricultural land system reform will usher in the agricultural modernization bright future.

\section{First, the Meaning of Agricultural Land Law System}

In general, land is a specific part of the earth. But it is what part of the Earth, which elements constitute a long time people's understanding is not consistent. This is mainly due to people's understanding of land with the development of social productive forces, the expansion of land use, land use intensity, land function changes and the continuous development and deepening of the understanding of the concept of land has a historical process . Here are some of the more accepted domestic theoretical point of view.

Just as academic research on the land system, scholars on the agricultural land system is based on the expression of their respective research perspective formed. Therefore, when the research perspective is the same, the connotation of the agricultural land system with a similar description of the characteristics of the; and when the research perspective is different, its presentation is quite different. Combining the above research on the land system, I believe that "agricultural land system" should include the following two aspects of meaning. First, the agricultural land system is in a certain social conditions, to farmland as a medium to form the relationship between people, and the relationship between the state and people. Second, the agricultural land system has broad and narrow sense. The broad agricultural land system includes all related farmland system. The narrow land system includes the farmland ownership system, the use system, the management system and the circulation system.

Combined with the above land system research, the agricultural land system refers to the sum of the economic and legal relations including the agricultural land ownership system, the agricultural land use system, the agricultural land circulation system and the farmland national management system. Second, the rural land law system of the external environment Agricultural land system is not an isolated system and it must be compatible with its institutional environment, but also for its institutional environment. Therefore, in the study of agricultural land system, it is necessary to understand its institutional environment. In a sense, the environment itself is an institutional arrangement. American institutional economist Davies argues that the laws that govern American elections, property rights, and contractual rules constitute the economic environment of the United States. He argues that in the US economy, the environment has been traced back to the founding of the republic through written documents, the interpretation of judicial decisions, and the institutional model of national citizens about their preferences.

Basic economic system environment of farmland system. According to Marxist theory of social stage, there are two different stages of social development in the world today, one is the stage of socialism and one is the stage of capitalism, the corresponding economic system, respectively, the socialist system and capitalism system. One of the basic characteristics of the socialist system is the implementation of public ownership of the means of production, mainly including the state-owned and collective-owned two types. Under the conditions of the public ownership of the means of production, the laborer is the main body of the means of production, and the laborers share the means of production within a certain scope. Labor becomes people's self-consciousness, and the laborers are treated according to their old incomes, hard work and inexpensiveness. Allowing any economic agent to own the labor of others by virtue of their ownership of the means of production has become the basic mode of production of the socialist system. This public ownership of the means of production forms the basic condition of China's agricultural land system. A basic characteristic of the capitalist 
system is that the means of production are private and are based on wage labor. Capitalists and laborers are employed and employed, and capitalists acquire capital by the surplus labor of the laborers. Capitalist means of production Private ownership forms the basis of the agricultural land system of the capitalist countries.

The basic political system environment of agricultural land system. Marxism believes that the economic base determines the superstructure, the superstructure on the economic base has a reverse effect. What kind of socio-economic system will have a corresponding political system, but the political system is not negative, it will also reactively react to the economic system. By the nature of the economic base, the agricultural system of political system environment is bound to be different with the economic base. China implements the people's congress system, which embodies the people's nature, therefore, the people of China's agricultural land system is the largest political environment. Capitalist countries, the parliamentary system, this representative of the representative of the bourgeois democracy, the interests of the capitalist countries, agricultural land system must also reflect the oligarchy of its face, that is, reflect its monopoly side. However, no matter what kind of social system, will show the country's institutional arrangements in the important role, it is generally believed that the state in the use of mandatory means for institutional arrangements have enormous economies of scale, is any other economic and political organization Unmatched, state-led mandatory institutional change than other forces to promote the induced institutional change is much lower cost, a lot of time will be more revenue. Of course, induced institutional changes can often be turned into a state-led mandatory institutional change. China's third agricultural land reform is a typical example.

The cultural and ideological environment of the agricultural land system. Culture and ideology have never been isolated, nor are they immutable. Culture and ideology cannot decide the arrangement of agricultural land system, but it has a very important influence on the arrangement of agricultural land system, and sometimes even has a great impact on the arrangement of macroeconomic policy. Chinese civilization originated in agricultural civilization, agricultural civilization is the foundation of Chinese civilization, in the history of the world it has long lead the development of world civilization, even in the industrialization of globalization today, this civilization is still in the forest of the world in a place in the forest of civilization. Farming civilization makes the Chinese nation life and life goes on and off five thousand years, for the development of world civilization has made important contributions. However, agricultural civilization has its limitations, due to the small number of people and the growth of seasonal restrictions on crops and other characteristics, coupled with "Chicken dog phase smell, old age does not contact" farming culture, resulting in China's own unique agricultural concept, awareness. Small farmers tend to evenly distributed, operating on the implementation of self-sufficiency, the remaining claim on the small rich that security. This kind of small-scale peasant consciousness is not suited to the development of large-scale industrial civilization. However, due to the traditional preference, it has deep impact on the arrangement of China's agricultural land.

The external environment of China's agricultural land system is an extension of the concept, in addition to the direct impact on the agricultural system outside environment and it is also subject to greater external system of influence and constraints. Nowadays, China is under unprecedented pressure of external environment change. Faced with the pressure of multiple external environment, how to do both to unswervingly hold high the great banner of socialism with Chinese characteristics, while the Western capitalist powers surrounded by the encirclement of the encirclement, to achieve our development strategy, which is in our country In the system reform.

\section{The Direction of Rural Land Law Reform}

Promote industrialization and accelerate urbanization. To speed up the process of industrialization and urbanization and realize the transfer of agricultural population is an effective way to solve the contradiction between man and land. On the one hand, urbanization can produce agglomeration effect, more intensive use of agricultural land, a negative correlation between the two, 
China's 668 cities in $0.2 \%$ of the land area, the accumulation of $16 \%$ of the population. On the other hand, the process of urbanization is also the non-agricultural transfer of rural population, the transfer of rural population to change the relative quantity of human resources, urban farmers with income levels and income diversification, will voluntarily Cut off the link with the agricultural land, to promote their own transfer and the transfer of farmland, farmers small household management pattern can be changed, the industrialization of agriculture, mechanization, large-scale operation can be achieved.

Cultivate farmland circulation market and guide moderate scale operation. Farmland is one of the most basic production factors. Without the agricultural land circulation market, the flow of factors will be greatly limited, and it is difficult to optimize the allocation of resources. The transfer of the right to use farmland is the intrinsic attribute and basic requirement of the market economy, because only the flow can achieve the optimal allocation, only to enter the market can produce exchange value. The history of economic development at home and abroad shows that the main way to optimize the allocation of all rare resources is the transfer of circulation. After the farmland circulation market is formed, it can break the community boundary of farmland resource allocation. The circulation of peasants' management right of farmland is no longer restricted by the collective space of the community, and can carry on the independent transfer and obtain the fair and reasonable management right.

Formulate the agricultural subsidies and other financial support agricultural policy. With the development of urbanization, agricultural land greatly reduced many rural people to the city to work, resulting in agricultural land barren and agricultural development challenges. To this end, the future of China may consider further increase subsidies, optimize the subsidy structure, increase farmers' enthusiasm for grain production, improve agricultural production and ensure China's food security. The second is to further increase the overall support for rural development. From the EU's reform program, a focus is from the direct subsidies for farmers to support the direction of rural development tilt, through insurance and mutual funds and other forms to ensure the interests of farmers, promote balanced and balanced development of rural areas. Relatively speaking, most of China's rural areas are still lagging behind the current level of development, low income farmers, agricultural infrastructure is weak. Therefore, it is the focus of China's rural areas to further strengthen the overall support for rural development, strengthen the construction of agricultural infrastructure, increase investment in agricultural science and technology, take coordinated measures to protect the interests of farmers and improve their living standards. The third is to address climate change, focusing on environmental protection and food safety. Agriculture is the most direct victim of climate change, and agricultural production has an important role in environmental change.

\section{Conclusion}

China's rural land family contract management system, as the most basic economic system in China's rural areas, it has played an important role in the process of agricultural modernization in China and has promoted the comprehensive development of China's rural economy and society. In fact, the establishment of rural land family contract management system did not exhaust the limits of rural land system innovation. In recent years, a series of profound changes have taken place in China's rural areas, which not only changed the external environment of rural land system innovation, but also put forward new requirements for the reform of rural land system. The author firmly believes that through a series of agricultural land system reform it will usher the bright future of agricultural modernization.

\section{References}

[1] B. N. Ma, Chinese rural land system arrangement and agricultural performance, J. China Rural Survey. 44 (2010) 146-147. 
[2] H.X.Zeng, Some Ideas on Rural Financial Reform, J. The Dynamics of Economics. 18(2005) 55-57.

[3] J.H.Xue, Agricultural public investment, competitiveness and food security, J. Economic Research, 32(2012) 189-190.

[4] Y.J.Qi, Arrangement of rural land system and agricultural structure in china, J, China Rural Survey, 4(2007) 38-40.

[5] Y.M.Tian, The Role of Structural Adjustment in Chinese Agricultural Growth, J. China Rural Economy, 9(2013) 142-150. 